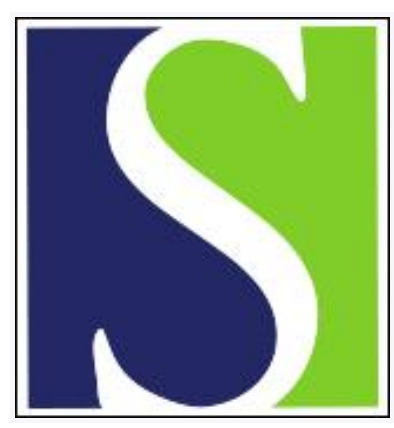

Scand J Work Environ Health 1998;24(1):12-17

https://doi.org/10.5271/sjweh.273

Issue date: Feb 1998

Mortality from asthma and cancer among sulfite mill workers

by Andersson E, Nilsson T, Persson B, Wingren G, Torén $K$

The following articles refer to this text: 2002;28(2):117-123;

2002;28(5):333-340; 2007;33(6):470-478

Key terms: brain tumor; case-referent study; epidemiology; lung cancer; mortality; obstructive lung disease; stomach cancer

This article in PubMed: www.ncbi.nlm.nih.gov/pubmed/9562396 


\title{
Mortality from asthma and cancer among sulfite mill workers
}

\author{
by Eva Andersson, MD, ${ }^{1}$ Tohr Nilsson, MD, ${ }^{2}$ Bodil Persson, MD, ${ }^{3}$ Gun Wingren, PhD, ${ }^{3}$ \\ Kjell Torén, $M D^{\prime}$
}

\begin{abstract}
Andersson E, Nilsson T, Persson B, Wingren G, Torén K. Mortality from asthma and cancer among sulfite mill workers. Scand J Work Environ Health 1998:24(1):12-7.
\end{abstract}

\begin{abstract}
Objectives The aims of the present case-referent study were to investigate whether sulfite workers show increased mortality from asthma, chronic obstructive pulmonary disease or certain malignancies of interest in relation to sulfite mill work. The main exposure from the pulping processes is from sulfur dioxide, wood dust and terpenes.

Methods The subjects of the study were all the men who died between 1960 and 1989 and who were aged 40 to 75 years at death $(\mathrm{N}=780)$ in the parishes surrounding 3 sulfite mills. The men who died from asthma ( $N=13)$, COPD $(N=20)$, lung cancer $(N=33)$, stomach cancer $(N=35)$, or brain tumor $(N=10)$ formed the case group. All the subjects, except the cases in question, were used as referents. As a proxy variable of exposure, job titles from the registers of deaths and burials were used, and $24 \%$ of the subjects were classified as exposed.

Results There was an increased mortality from asthma [odds ratio(OR) $2.8,90 \%$ confidence interval (90\% CI) $1.1-6.8$ ] and brain tumors (OR 3.3, 90\% CI 1.2-8.9) among the sulfite workers. The mortality due to lung cancer was not significantly increased (OR 1.4, 90\% CI 0.7-2.6), and there was a reduced mortality from stomach cancer (OR $0.4,90 \% \mathrm{CI} 0.2-0.9$ ).

Conclusions The increased asthma mortality may be due to accidental exposure to irritating gases, such as sulfur dioxide. The increased risk for brain tumors has no obvious explanation.
\end{abstract}

Key terms brain tumor, case-referent study, epidemiology, lung cancer, mortality, obstructive lung diseases, stomach cancer.

The production of pulp and paper is an important industrial trade in Sweden. This work environment entails a variety of exposures depending on the process, and 2 main processes can be distinguished, the acidic sulfite process and the alkaline sulfate process. The main occupational exposure in sulfite mills is to sulfur dioxide, wood dust, and terpenes (1).

Mortality studies on pulp mill workers seldom analyze nonmalignant respiratory diseases such as obstructive airway diseases. Jäppinen \& Tola (2) noted an excess of deaths from nonmalignant respiratory diseases [standardized mortality ratio (SMR) 230, 95\% confidence interval (95\% CI) 84-500] among male pulp mill workers exposed to sulfur dioxide. Wingren et al (3) noted a slightly increased risk for obstructive airway diseases [odds ratio (OR) 1.3, 90\% CI 0.9-1.9] among "pulp and paper" workers. Among pulp mill workers, the development of obstructive airway disease after accidental exposure to sulfur dioxide has also been shown in case reports (1), and it also occurs in other environments (4).

Whether sulfite workers have an increased risk for cancer has been discussed in the literature $(5,6)$. In regard to stomach cancer, both increased and decreased risks have been found $(5,6)$. Among unspecified pulp mill workers, an increased risk for lung cancer from exposure to asbestos has been described, although not among sulfite mill workers (6).

An increased risk for intracranial gliomas [standardized incidence ratio (SIR) $1.6(\mathrm{P}<0.01)]$ has been observed among male cellulose plant employees in a study based on the Swedish cancer environment register for the years 1961-1979 (7). A nonsignificant increase in brain tumors was observed among paper product manufacturers in a casereferent study based on American death certificates (OR 1.9, $95 \%$ CI $0.6-6.3)(8)$.

1 Department of Occupational Medicine, Sahlgrenska University Hospital, Göteborg, Sweden.

2 Department of Occupational Medicine, Sundsvall General Hospital, Sundsvall, Sweden.

3 Department of Occupational and Environmental Medicine, Faculty of Health Sciences, Linköping, Sweden.

Reprint requests to: Dr Eva Andersson, Department of Occupational Medicine, Sahlgrenska University Hospital, St Sigfridsgatan 85B, S-412 66 Göteborg, Sweden. 
The main aim of the present study was to investigate whether sulfite mill workers experience an increased mortality from obstructive airway diseases, especially asthma. We also wanted to determine whether sulfite mill workers have increased mortality from lung cancer, stomach cancer, or brain tumors.

\section{Subjects and methods}

The 3 old sulfite mills selected for the study were located in rural areas and were the dominant industries in their regions. Other than small industries, the sulfite mill was the only factory. Its pulp production never exceeded 100000 metric tons annually. The subjects for the study ( $\mathrm{N}=780)$, cases and referents, were obtained from the local registers of deaths and burials in 3 parishes, each surrounding a sulfite mill. In Sweden, all deaths were reported to such local parish registers of deaths and burials, which were kept in each parish. The registered cause of death was based on information from the death certificates. The study was restricted to men aged 40 to 75 years at death, and it covered the period between 1960 and 1989.

The underlying causes of death were reclassified according to the International Classification of Diseases (ICD), 8th revision (ICD-8). Cancer was always coded as an underlying cause of death, and we gave priority to chronic obstructive pulmonary disease in relation to asthma. In addition, some contributing causes of death of special interest, namely, asthma (ICD-8 493) and chronic obstructive pulmonary disease (ICD-8 490-492), were also coded when appearing as a cause of death. This design also made it possible to study case entities not directly lethal to the persons in question.

Cases (underlying and contributing causes of death) for the study were asthma (ICD-8 493) $(\mathrm{N}=13)$, chronic obstructive pulmonary disease (ICD-8 490 - 492) (N=20), stomach cancer (ICD-8 151) $(\mathrm{N}=35)$, lung cancer (ICD-8 162) $(\mathrm{N}=33)$, and brain tumors (ICD-8 192) $(\mathrm{N}=10)$. Except for the cases in question, all the subjects were used as referents. However, when asthma was analyzed, the subjects with chronic obstructive pulmonary disease were excluded from the reference group.

For 7 cases with asthma ( 7 of 13) and for 7 cases with chronic obstructive pulmonary disease ( 7 of 20 ), the diagnosis was based on the underlying cause of death. Copies of the original death certificates were obtained for 31 of the 33 cases with asthma or chronic obstructive pulmonary disease, and they were all in agreement with the diagnoses obtained from the registers of death and burials. For 26 of the 33 cases, we obtained access to hospital files, and for another 2 we obtained data on their diseases from the trade union. The information obtained from these sources was of varying quality, but nothing contradicted our classification of the causes of death.
Table 1. Number of deceased men aged $40-75$ years and their exposure frequency in each parish surrounding a sulfite mill.

\begin{tabular}{lcccc}
\hline Parish & $\begin{array}{c}\text { Number } \\
\text { included }\end{array}$ & $\begin{array}{c}\text { Exposed } \\
(\%)\end{array}$ & \multicolumn{2}{c}{ Number } \\
\cline { 4 - 5 } & & & \multicolumn{2}{c}{ Exposed Unexposed } \\
\hline A & 280 & 20.4 & 57 & 223 \\
B & 230 & 17.0 & 39 & 191 \\
C & 270 & 33.3 & 90 & 180 \\
\hline Total & 780 & 24.0 & 186 & 594 \\
\hline
\end{tabular}

According to information from the Swedish Cancer Register, 9 of the 10 brain tumors were classified as gliomas and 1 was categorized as an unspecified brain tumor. Eight were diagnosed histologically and 2 radiologically. The diagnoses of lung and stomach cancer were not validated further.

We were not able to obtain personnel files from the actual mills. In the registers of deaths and burials, there is 1 job title mentioned that probably reflects the predominant position held. Job title was used as a proxy exposure variable. The occupational titles "sulfite worker" or "factory worker" were regarded as exposed, and subjects with other titles were classified as unexposed. For the exposed cases with asthma or chronic obstructive pulmonary disease $(\mathrm{N}=11)$ and brain tumors $(\mathrm{N}=5)$, additional information about worktasks and periods of employment was obtained from the trade union.

The study included 780 men (table 1), and, of these, $24 \%$ were classified as exposed according to their job titles.

The statistical analysis was based on Mantel \& Haenszel (9). When calculating the Mantel-Haenszel odds ratios $\left(\mathrm{OR}_{(\mathrm{M}-\mathrm{H})}\right)$, the subjects were stratified according to age (4065 years and $66-75$ years). The calculation of test-based $90 \%$ confidence intervals was based on a method outlined by Miettinen (10). In addition, crude odds ratios were calculated using a level of significance based on Fisher's exact test.

\section{Results}

There was an increased mortality from asthma and chronic obstructive pulmonary disease $\left(\mathrm{OR}_{(\mathrm{M}-\mathrm{H})} 1.6,90 \% \mathrm{CI} 0.9-\right.$ 3.0 ), with underlying and contributing causes merged (table 2 ). When the analysis was restricted to only asthma, with the underlying and contributing causes merged, the risk increased $\left(\mathrm{OR}_{(\mathrm{M}-\mathrm{H})} 2.8,90 \% \mathrm{CI} 1.1-6.8\right.$, crude odds ratio $2.8, \mathrm{P}=0.06$ ) (table 3 ). When only asthma as the underlying cause of death was included, the crude odds ratio was $2.5(\mathrm{P}=0.21)$. The asthma cases were evenly distributed over the years. The exposed asthma cases are further described in table 4.

The risk of stomach cancer was decreased among the sulfite mill workers (table 5). There was no significantly increased risk for lung cancer (table 5). 
The risk of brain tumors was increased $\left(\mathrm{OR}_{(\mathrm{M}-\mathrm{H})} 3.3\right.$, $90 \% \mathrm{CI} 1.2-8.9)$, as shown in table 5 . The crude odds ratio was $3.2(\mathrm{P}=0.06)$. For 3 of the 5 exposed cases, we obtained supplementary exposure information. Two of them had been working in the wood room and 1 in the bale room (finishing room). Their periods of employment were 11,34, and 45 years, respectively. The time between the start of employment and diagnosis was 15,50 , and 45 years, respectively.

Table 2. Number of cases with asthma and chronic obstructive pulmonary disease as cause of death (underlying and contributing causes) and referents in a study of sulfite workers in 19601989. The Mantel-Haenszel odds ratio (OR $(\mathrm{M}-\mathrm{H}))$ has been stratified for age.

\begin{tabular}{|c|c|c|c|c|c|}
\hline & $\begin{array}{l}\text { Exposed } \\
\text { (N) }\end{array}$ & $\begin{array}{l}\text { Unexposed } \\
\text { (N) }\end{array}$ & $\begin{array}{c}\text { Crude } \\
\text { odds ratio }\end{array}$ & $O R_{(M-H)}$ & $90 \% \mathrm{Cl}$ \\
\hline Cases & 11 & 22 & \multirow{2}{*}{$1.6\left(P=0.13^{a}\right)$} & \multirow{2}{*}{1.6} & \multirow{2}{*}{$0.9-3.0$} \\
\hline Referents & 175 & 572 & & & \\
\hline
\end{tabular}

a Fisher's exact test

Table 3. Number of cases and referents with asthma as cause of death (underlying and contributing causes) and referents in a study of sulfite workers in 1960-1989. The Mantel-Haenszel odds ratio $\left(O R_{(M-H)}\right)$ has been stratified for age.

\begin{tabular}{|c|c|c|c|c|c|}
\hline & $\begin{array}{l}\text { Exposed } \\
(\mathrm{N})\end{array}$ & $\begin{array}{l}\text { Unexposed } \\
\text { (N) }\end{array}$ & $\begin{array}{c}\text { Crude } \\
\text { odds ratio }\end{array}$ & $O R_{(M-K)}$ & $90 \% \mathrm{Cl}$ \\
\hline Cases & 6 & 7 & \multirow{2}{*}{$2.8\left(P=0.06^{a}\right)$} & \multirow{2}{*}{2.8} & \multirow{2}{*}{$1.1-6.8$} \\
\hline Referents & 175 & 572 & & & \\
\hline
\end{tabular}

a Fisher's exact test.

\section{Discussion}

In the present study on sulfite workers, an increased mortality from asthma and brain tumors was observed. The mortality from stomach cancer was reduced.

\section{Methodological considerations}

The study design has certain limitations, such as the exposure assessment. The exposure was based upon job titles obtained from the local registers of deaths and burials, and therefore we were only able to classify the subjects as exposed or unexposed. It was not possible to classify the subjects according to their relevant exposure to sulfur dioxide, asbestos, and so on. In our experience, the title of factory worker has only been used for subjects employed in mills and other such large enterprises. From the trade union, we searched for information about some of the cases (asthma or chronic obstructive pulmonary disease + brain tumors) that we had identified as being exposed according to their job titles. Information was available only from 2 of the mills, but all 14 of the subjects searched for there had been sulfite mill workers. This finding indicates that the positive predictive value of such job titles in this industry is high. Migration is minimal in rural areas, and, in parishes like these, people often hold the same job for a long time. Subjects who only worked a short time at the mill would probably be classified as unexposed. The prevailing exposure misclassification is regarded as nondifferential in relation to the effects of interest, and hence the risk will be biased towards unity.

In the validation of the diagnoses we focused on asthma, chronic obstructive pulmonary disease, and brain tumors.

The most important misclassification was that between asthma and chronic obstructive pulmonary disease, which is more manifest among older subjects (11). There may also

Table 4. Data on year of birth and death, period of employment, working department, and asthma disease for the male sulfite mill workers with asthma as a cause of death.

\begin{tabular}{|c|c|c|c|c|c|}
\hline & Life span & $\begin{array}{l}\text { Period of } \\
\text { employment }\end{array}$ & $\begin{array}{l}\text { Department } \\
\text { where worked }\end{array}$ & $\begin{array}{l}\text { Age at onset } \\
\text { of asthma }\end{array}$ & $\begin{array}{l}\text { Additional } \\
\text { information }\end{array}$ \\
\hline Worker 1 & $1900-1964$ & $1927-1954$ & Digester house & 45 & $\begin{array}{l}\text { After gassing accident, } \\
\text { transferred to other } \\
\text { departments because of } \\
\text { asthma; disability } \\
\text { pension in } 1954\end{array}$ \\
\hline Worker 2 & $1903-1970$ & $1924-1950$ & Wood room & $56 ?$ & .. \\
\hline Worker 3 & $1903-1972$ & $1923-1958$ & Acid tower & $40^{\mathrm{a}}$ & $\begin{array}{l}\text { Transferred to other } \\
\text { departments because of } \\
\text { asthma; disability pension } \\
\text { in } 1958\end{array}$ \\
\hline Worker 4 & $1906-1972$ & $1926-1950 ?$ & $\begin{array}{l}\text { Acid tower, } \\
\text { digester house }\end{array}$ & $38^{\mathrm{a}}$ & $\begin{array}{l}\text { Disability pension } \\
\text { (asthma) }\end{array}$ \\
\hline Worker 5 & $1908-1974$ & $1920 ?-1965$ & Digester house & 42 & $\begin{array}{l}\text { Several gassing accidents } \\
\text { from } 1922 \text {; transferred } \\
\text { in } 1954 \text { to other depart- } \\
\text { ments because of asthma; } \\
\text { disability pension in } 1965\end{array}$ \\
\hline Worker 6 & $1914-1988$ & $1950-1968$ & Wood room & $50 ?^{a}$ & \\
\hline
\end{tabular}

a Underlying cause of death. 
have been a greater degree of misclassification for the contributing causes of death than for the underlying causes of death. The age of asthma onset for the exposed workers varied from 38 to 56 years of age, and therefore it was likely that asthma was correctly diagnosed. We also gave priority to chronic obstructive pulmonary disease; therefore, if both asthma and chronic bronchitis or emphysema was mentioned in the death certificate, we only coded them as chronic obstructive pulmonary disease. Since obstructive lung disease has generally not been known to be related to sulfite mill work, we did not expect differential misclassification.

The possible diagnostic misclassification of brain tumors was reduced by validating the diagnosis against that in the national cancer register. There is no reason to believe that the misclassification of tumor diagnoses is dependent on the subjects' exposure status.

Selection bias (the healthy worker effect) is certainly present when obstructive airway diseases are studied. Mill workers with asthma or chronic obstructive pulmonary disease may change jobs and thus not be titled as sulfite or factory workers. The healthy worker effect is less important when cancers are studied (12).

Smoking is probably a weak confounder for asthma, but for lung cancer its confounding properties are more obvious. The association between asthma and smoking has not been established, but some authors have found an increased risk $(13,14)$. Although the smoking status of the subjects was not known, in 1 of the mill communities, the prevalence of male ever smokers (ex-smokers + smokers) was 54\%, as compared with $67 \%$ among the male mill workers (15). On the assumption that these proportions are valid for the whole study population, we can adjust for confounding in relation to both asthma and lung cancer (16). If the risk for developing asthma for smokers is assumed to be $1.9(14)$, the crude odds ratio will decrease from 2.8 to 2.6. If the risk of ever smokers contracting lung cancer is 8.3 (17), the crude odds ratio for lung cancer will decrease from 1.4 to 1.2. The subjects in the study were selected from the population in the neighborhood of the mills. Hence the subjects may have been environmentally exposed to effluents from the mills, the result being an underestimation of the risk. However, in a previous study, the prevalence of asthma or chronic bronchitis among people living near 1 of the mills was similar to that of people living in the peripheral agricultural area (15).

\section{Obstructive airway diseases}

There are only a few studies reporting on asthma in pulp mill workers. Increased mortality from asthma has been described for debarkers at 2 sulfite mills (18), as has an increased prevalence of asthma among debarkers in a pulp mill (19). Stjernberg found no difference in the prevalence of asthma (3.9\% versus $3.4 \%$ ) between male mill and nonmill workers in 1 of the mill communities (15). This finding may have been the result of a healthy worker effect, as the
Table 5. Cases with stomach cancer, lung cancer, and brain tumors and referents in a study of male sulfite mill workers in 1960-1989. The relative risks $\left(O R_{\left(M-H_{1}\right)}\right)$ have been calculated according to Mantel-Haenszel, stratified for age. $(90 \% \mathrm{Cl}=90 \%$ confidence interval)

\begin{tabular}{lrrcc}
\hline $\begin{array}{l}\text { Site of } \\
\text { cancer }\end{array}$ & $\begin{array}{c}\text { Exposed } \\
(\mathrm{N})\end{array}$ & $\begin{array}{c}\text { Unexposed } \\
(\mathrm{N})\end{array}$ & $\mathrm{OR}_{(\mathrm{M}-\mathrm{H})}$ & $90 \% \mathrm{Cl}$ \\
\hline Stomach & & & 0.4 & $0.2-0.9$ \\
$\quad$ Cases & 4 & 31 & & \\
$\quad$ Referents & 182 & 563 & & \\
Lung & & & 1.4 & $0.7-2.6$ \\
$\quad$ Cases & 10 & 23 & & \\
$\quad$ Referents & 176 & 571 & & \\
Brain & & & 3.3 & $1.2-8.9$ \\
$\quad$ Cases & 5 & 5 & & \\
$\quad$ Referents & 181 & 589 & & \\
\hline
\end{tabular}

authors found a high frequency of asthma in elderly men who had earlier worked at the mill (20).

The development of obstructive airway disease after accidental exposure to irritant gases is well established (21, 22). Four of the 6 exposed asthma cases in the present study had been working in the acid tower or digester house. We know that at least 2 of them had experienced serious gassing incidents and had developed their asthma after these incidents. Five of them developed asthma while they were employed. According to the hospital files, another asthma case, classified as unexposed, had contracted his asthma after a gassing accident at work. Asthma and bronchial hyperreactivity may also be the result of recurrent exposure to irritants, but the epidemiologic evidence for such an association is still weak (22).

In a Finnish cohort study of pulp and paper workers, the mortality from diseases of the respiratory system was higher for sulfite workers (SMR 155, 95\% CI 83-265) (23). When the data from that study were further analyzed, the subgroup of workers exposed to sulfur dioxide showed an increased mortality from nonmalignant respiratory diseases (SMR 230, 95\% CI 84-500) (2). The data from a previous study on pulp and paper workers (3) have been recalculated, and the recalculation indicates an increased risk for asthma $\left(\mathrm{OR}_{(\mathrm{M}-\mathrm{H})} 1.9,95 \% \mathrm{CI} 0.95-4.0\right)$ (Persson, personal communication).

It is important to realize that, even though this study was based on a remote time period, exposure to sulfur dioxide remains a problem in pulp mills. Even during the last few years, we have clinically examined several cases that have developed severe obstructive airway disease after accidental exposure to sulfur dioxide.

Our study showed an increased mortality from asthma among sulfite mill workers, and it seems reasonable to assume that exposure to sulfur dioxide is the main risk factor.

\section{Brain tumors}

The accepted risk factors, inherited predisposition and ionizing radiation, are responsible for only a small fraction of 
brain tumors. In a recent review of the etiology of brain tumors in adults, the authors concluded that little is known (24). Electric and magnetic fields have been discussed in the etiology of brain tumors, but the studies are inconclusive. If there is an increase in the risk, it is probably small, only $10 \%$ to $20 \%$, according to a recent meta-analysis (25). Measurements of $60-\mathrm{Hz}$ electric and magnetic field levels from 3 pulp and paper mills in Canada using spot (area point-in-time) measurements showed field levels similar to those experienced by the general population (26). For magnetic fields, the median was $0.16 \mu \mathrm{T}(0.01-71 \mu \mathrm{T})$.

In our study, we were not able to draw any conclusions about the causes of the observed risk increase. It is, however, of interest that a recently published cohort study of pulp and paper mill workers found increased mortality (SMR 1.51, $90 \%$ CI 1.03-2.16) for brain cancer (27). There is also a case-referent mortality study among sulfate mill workers that reports overrisk (OR 2.6, 95\% CI 1.1-6.1) for brain tumors (28).

\section{Stomach cancer}

There are several studies indicating an increased risk for stomach cancer among pulp mill workers (6). A few studies separating different processes indicate an increased risk among sulfite mill workers (6). Our study showed, however, a reduced risk. Considering the fact that the possible occupational risk factor has not been identified, we think the relationship between stomach cancer and sulfite mill work is doubtful.

\section{Lung cancer}

The risk of lung cancer was increased without reaching statistical significance. Increased risk for lung cancer has earlier been observed among pulp and paper mill workers, probably caused by exposure to asbestos (6). In our study, we were not able to analyze the data on the maintenance workers separately, a group of interest regarding asbestos exposure.

\section{Concluding remarks}

In conclusion, the present study from 3 Swedish sulfite mills shows an increased risk for asthma. The increased risk may be the result of accidental exposure to sulfur dioxide or other irritants. There was also an increased risk for brain tumors. This observation has no obvious biological explanation but needs to be further investigated.

\section{Acknowledgments}

The study was supported by the Swedish Council for Worklife Research and the Emil Anderssons Minnesfond.

\section{References}

1. Torén $\mathrm{K}$, Hagberg S, Westberg H. Health effects of working in pulp and paper mills: exposure, obstructive airways diseases, hypersensitivity reactions and cardiovascular diseases. Am J Ind Med 1996;29:111-22.

2. Jäppinen P, Tola S. Cardiovascular mortality among pulp mill workers. Br J Ind Med 1990;47:259 -62 .

3. Wingren $\mathrm{G}$, Persson $\mathrm{B}$, Thorén $\mathrm{K}$, Axelson O. Mortality pattern among pulp and paper mill workers in Sweden: a case-referent study. Am J Ind Med 1991;20:769-74.

4. Piirilä PL, Nordman H, Korhonen OS, Winblad I. A thirteen-year follow-up of respiratory effects of acute exposure to sulfur dioxide. Scand J Work Environ Health 1996;22:191-6.

5. International Agency for Research on Cancer (IARC). Wood, leather and some associated industries. Lyon: IARC, 1980. IARC monographs on the evaluation of carcinogenic risks to humans, vol 25 .

6. Torén $\mathrm{K}$, Persson B, Wingren $\mathrm{G}$. Health effects of working in pulp and paper mills: malignant diseases. Am J Ind Med 1996;29:12330.

7. McLaughlin JK, Malker HSR, Blot WJ, Malker BK, Stone BJ, Weiner JA, et al. Occupational risks for intracranial gliomas in Sweden. INCI 1987;78:253 7 .

8. Demers PA, Thomas L, Vaughan MTL, Schommer RR. Occupation, socioeconomic status, and brain tumor mortality: a death certificatebased case-control study. J Occup Med 1991;33:1001-6.

9. Mantel N, Haenszel W. Statistical aspects of the analysis of data from retrospective studies of disease. JNCI 1959;22:719-48.

10. Miettinen OS. Estimability and estimation in case-referent studies. Am JEpidemiol 1976;103:226-35.

11. British Thoracic Association. Accuracy of death certificates in bronchial asthma. Thorax 1984;39:505-9.

12. Howe GR, Chiarelli AM, Lindsay IP. Components and modifiers of the healthy worker effect: evidence from three occupational cohorts and implications for industrial compensation. Am J Epidemiol 1988; $128: 1364-75$.

13. Vesterinen E, Kaprio J, Koskenvuo M. Prospective study of asthma in relation to smoking habits among 14729 adults. Thorax 1988; $43: 5349$.

14. Flodin U, Jönsson P, Ziegler J, Axelson O. An epidemiologic study of bronchial asthma and smoking. Epidemiology 1995;6:503-5.

15. Stjernberg N. Chronic bronchitis and bronchial asthma in an industrial community in northern Sweden: relation to environmental and occupational exposure to $\mathrm{SO}_{2}$ [dissertation]. Umeå: Department of Lung Medicine, University of Umeå, Sweden, 1985.

16. Axelson $\mathrm{O}$. Aspects on confounding in occupational health epidemiology [letter to the editor]. Scand J Work Environ Health 1978;4:98-102.

17. Doll R, Peto R. Mortality in relation to smoking: 20 years' observations on male British doctors. BMJ 1976;2:1525-36.

18. Torén K, Sällsten G, Järvholm B. Mortality from asthma, chronic obstructive pulmonary disease, respiratory system cancer and stomach cancer among paper mill workers: a case referent study. Am J Ind Med 1991; 19:729-37.

19. Niemelä SI, Vaätänen P, Mentu J, Jokinen A, Jäppinen P, SillanpääP. Microbial incidence in upper respiratory tracts of workers in the paper industry. Appl Environ Microbiol 1985;50:163 — 8.

20. Mikaelsson B, Stjernberg N, Wiman L-G. The prevalence of bronchial asthma and chronic bronchitis in an industrialized community in nothern Sweden. Scand J Soc Med 1982;10:11 —6.

21. Brooks SM, Weiss MA, Bernstein IL. Reactive airways dysfunction syndrome (RADS). Chest 1985;88:376-84.

22. Kennedy SM. Acquired airway hyperresponsiveness from nonimmu- 
nogenic irritant exposure. Occup Med 1992;7:287-300.

23. Jäppinen P. A mortality study of Finnish pulp and paper workers. Br J Ind Med 1987;44:580-7.

24. Inskip PD, Linet MS, Heineman EF. Etiology of brain tumors in adults. Epidemiol Rev 1995;17:382-414

25. Kheifets LI, Afifi AA, Buffler PA, Zhang ZW. Occupational electric and magnetic field exposure and brain cancer: a meta-analysis. J Occup Environ Med 1995;37:1327-41.

26. Barroetavena MC, Ross R, Teschke K. Electric and magnetic fields at three pulp and paper mills. Am Ind Hyg Assoc J 1994;55:358_63.
27. Band PR, Le ND, Fang R, Threlfall WJ, Astrakianakis G, Anderson JTL, et al. Cohort mortality study of pulp and paper mill workers in British Columbia, Canada. Am J Epidemiol 1997;146:186 —94.

28. Andersson E, Hagberg S, Nilsson T, Persson B, Wingren G, Tơrén K. Cancer among sulphate mill workers - a case-referent mortality study. In: National Institute for Working Life. XXIV International Congress on Occupational Health, Stockholm 1996. Stockholm: National Institute of Working Life, 1996.

Received for publication: 20 March 1997 